\title{
Clinical importance of high- sensitivity troponin T in patients without coronary artery disease
}

\author{
(D) Lutfu Askin, (1) Okan Tanriverdi, (1) Serdar Turkmen \\ Department of Cardiology, Adiyaman Training and Research Hospital, Adiyaman, Turkey
}

\begin{abstract}
Cardiac troponin is the preferred biomarker for the diagnosis of the acute coronary syndrome (ACS), but many other diseases can be identified with elevated troponin levels in the absence of ACS. The recent development of a high-sensitive cardiac troponin T (hs-cTnT) assay permits the detection of very low levels of cTnT. The use of hs-cTnT assay has emerged as a tool for identifying high-risk individuals for primary preventive treatment and can detect subclinical injury in asymptomatic patients. Hs-cTnT analyses are generally related to ischemia in the literature. Thus, we made an evaluation of hs-cTnT analysis in noncoronary patients, which may contribute to the literature.
\end{abstract}

Keywords: Acute myocardial infarction; high sensitive cardiac troponin T; ischemia; subclinical damage.

Cite this article as: Askin L, Tanriverdi O, Turkmen S. Clinical importance of high- sensitivity troponin T in patients without coronary artery disease. North Clin Istanb 2020;7(3):305-310.

$\mathrm{B}$ lood levels of high-sensitivity cardiac troponin $\mathrm{T}$ (hs-c $\operatorname{Tn} \mathrm{T}$ ) is a useful biomarker for the evaluation of cardiac insufficiency, the pathogenesis of subclinical myocardial damage and can prediction of cardiovascular events [1]. Hs-c TnT is also a biomarker for myocardial infarction (MI), but many other diseases can also be identified with high troponin levels in the absence of MI. $\mathrm{Wu}$ et al. [2] showed that basal levels of hs-cTnT were associated with mortality, and most of the deaths were not associated with non-cardiovascular diseases. Highprecision testing improves analytical detection limits so that concentrations are measured in most healthy individuals. This ability allows the evaluation of variation to determine what constitutes a clinically important change in cardiac troponin concentration, a critical measure to identify acute events. Acute events are usually myocardial infarction, but any acute heart injury may cause these values to increase or decrease [3]. The biological variation of HscTnT is higher than cardiac troponin I, which can be attributed to differences in biology or assay sensitivity at low concentrations. A short-term reference point and a long-term reference point are required to define a changing pattern [4]. Prognostic value of Hs-cTnT had a strong association with the mortality rate among geriatric patients with or without coronary disease. The studies from Cardinaels et al. [5] and Lemos et al. [6] showed that mortality risk in geriatric patients without acute coronary syndrome was linked to increased basal hs-cTnT levels. Our main goal was to present an understanding of the many causes and prognostic significance of the hs-c TnT increase in other non-ACS diseases.

\section{The Association between hs-c TnT and Hypertension} Hypertension (HT) is an independent risk factor for cardiovascular and renal diseases. HT is the third most frequent cause of death, according to the World Health Organization [7]. Recently, biomarkers have been effective in the non-invasive detection of subclinical myocardial dam- 
age [8]. Notably, the affinity of hs-c'TnT levels secondary to structural heart disease was observed to be higher than epicardial coronary diseases in recent studies [9]. High hs-cTnT levels are linked to myocardial damage.

Patients with HT have significantly higher hs-c TnT levels when compared to healthy controls. Hs-cinT is important for the contraction of myocardium since it regulates the calcium-sensitive interaction between myosin and actin [10]. In patients without myocardial necrosis, hs-c TnT is not detectable with most of the conventional tests. Therefore, it can be used for prognosis in hypertensive patients. In addition, hs-cTnT values are positively correlated with left ventricular hypertrophy $(\mathrm{LVH})$ in hypertensive patients $[6,11,12]$. Sato et al. [12] reported that $78 \%$ of the essential hypertensive patients had hs-cTnT value of at least $0.003 \mathrm{ng} / \mathrm{ml}$. In addition, age, GFR and Cornell voltage were significantly related to hs-cTnT.

Høiseth et al. [13] reported a significant relationship between arterial hypertension and hscTnT, similar to creatinine levels and age. In patients with HT (even in the absence of ischemic heart disease) increased hs-c $\operatorname{TnT}$ levels, together with vascular remodeling and increased pressure, may disrupt microvascular function due to hypertrophy or systolic dysfunction. Non-dipper hypertensive patients are known to have more organ damage than dipper hypertensive patients [14]. Moreover, hs-cTnT can also help to identify the patients with the risk of last stage organ damage [15]. Hs-c TnT levels are found to be an independent determinant of pre-hypertension.

Askin et al. [16] showed that patients with pre-hypertension had higher hs-c $\mathrm{Tn} T$ levels and suggested that hs-cTnT can be used as a diagnostic biomarker in nondipper hypertension [17]. The mechanisms underlying the elevated hs-cTnT levels in hypertensive patients without ischemic heart disease are yet to be understood. Increased blood pressure may damage the coronary microvascular structure, remodel vascular structures or increase systolic or diastolic wall stress [18]. Left ventricular (LV) hypertrophy may cause decreased subendocardial coronary blood circulation and reduced myocardial ischemia tolerance by increasing RV end-diastolic pressure and wall stress.

Myocardial scarring and RV dysfunction may develop as a result of increased myocardial ischemia, leading to elevated hs-c TnT release [11]. Hs-c TnT can be a useful biomarker of future adverse cardiovascular or cerebrovascular disease in pre-hypertensive patients [19]. Mishra et al. [20] showed that detectable hs-c TnT was strongly associated with left ventricular hypertrophy (LVH) and RV geometry in patients with renal insufficiency. Hickman et al. [21] claimed that hs-cTnT could be secreted by membranous bubbles in cardiac myocytes during non-necrotic ischemia. In the 20-year follow-up study, increased hs-c $\operatorname{TnT}$ was found to be associated with HT [15].

A 52-month follow-up study showed that increased troponin levels were associated with cardiovascular events [19]. These findings present a promising approach for identifying high-risk patients at an early stage via troponin measurements. More sensitive analyses are now available, so lower troponin concentrations can be measured [22]. Arteriosclerosis measurements (heart rate wave velocity and heart rate pressure) are associated with increased cTnT level in subclinical myocardial damage in geriatric patients [23]. Furthermore, c $\operatorname{Tn} T$ was associated with age, renal function and cardiac hypertrophy in patients with treated essential HT [11]. Hs-TnT may indirectly reflect the degree of RV hypertrophy.

Elevated hs-TnT levels may be due to continued myocardial damage or leakage of myofibrillar components and reflect the permanent loss of cardiac myocytes in the development of hypertensive cardiac remodeling [24]. In addition to increased myocardial strain and neuroendocrine system abnormalities, cardiomyocyte apoptosis is another important cause of increased troponin levels [25]. Ucar et al. [26] showed that hs-cTnT levels were associated not only with LVH but also with LV geometry in hypertensive patients. Hs-cTnT can predict the worsening of albuminuria in HT [27]. Elevated hs-c TnT levels with increased ischemia can be another cause of disruption of myocardial performance index [28].

In the light of the above studies, we conclude that the Hsc TnT test is a very sensitive test and that Hsc TnT is detectable in almost all healthy individuals. Hsc TnT may have a strong association with systolic blood pressure (BP) and may be useful for direct measurement of subclinical myocardial damage associated with high BP. Further prospective studies are needed to confirm these hypotheses.

Role of hs-cTnT in the Prognosis of the Patients with Pulmonary Artery Hypertension (PAH)

Although elevated hs-cTnT levels were found to be useful to predict adverse hemodynamic and prognosis after acute PE (pulmonary embolism), its role in chronic PE is still controversial due to the potentially low use preva- 
lence [29]. Previous studies showed that detectable hscTnT levels in acute PE patients were associated with poor prognosis [30]. In diagnosed PE patients, 99\% cardiovascular prevalence of $\mathrm{Hs}-\mathrm{c} \mathrm{TnT}$ was reported to be $32 \%$ [31]. Elevated hs-cTnT levels are associated with increased heart rate, low oxygen saturation and significant exercise restriction in patients with pulmonary artery hypertension (PAH) [32].

On the contrary to acute $\mathrm{PE}$, the prevalence of the high levels of hs-cTnT is significantly lower in PAH. Torbicki et al. [32] first reported the potential prognostic role of hs-cTnT in PAH. Although the prevalence of detectable hs-cTnT was only $14 \%$, elevated levels were found to be associated with poor prognosis.

Pathological mechanisms underlying the increased hs-cTnT levels in chronic PAH patients or after acute $P E$ remain unclear. Various mechanisms like myocardial ischemia and necrosis due to an acute increase of hscTnT after RV or myocardial stress due to increased wall stress have been proposed. In PE, elevated hs-cTnT levels are associated with RV dysfunction [30,31]. In patients with chronic left-sided cardiac insufficiency, elevated hscTnT levels are correlated with decreased functional capacity and poor prognosis [33]. This is consistent with current findings in PAH with chronic RV dysfunction.

Significant RV dysfunction and decreased regional contractility during echocardiography were found in the patient with detectable levels for hs-TnT. Consistently, $\mathrm{RV}$ strain and strain velocity are inversely proportional to hs'TnT value, which is an indicator of systolic RV dysfunction. However, no association was found between diastolic RV dysfunction, Tei index and hs-TnT level [34]. In this context, echocardiography is an important indicator of pulmonary hemodynamic in smaller heterogeneous populations, including the patient with ischemic left ventricular insufficiency or $\mathrm{PAH}$ due to chronic thromboembolism [35].

Kriechbaum et al. [36] reported that hs-cTnT increased in patients with chronic thromboembolic pulmonary hypertension (CTEPH) and suggested that persistent subclinical myocardial damage potentially triggered due to increased RV pressure. HscTnT levels significantly decrease with balloon pulmonary angioplasty treatment and are correlated with reduced RV wall stress.

The increased pressure and/or pressure load leads to myocardial damage. In recent years, newly developed and sensitive methods for the detection of cardiac troponins are claimed to be effective in the assessment of myocardial damage in children with congenital heart disease (CHD) [37]. In CHD patients, $\mathrm{PAH}$ triggers myocardial damage independently from increased volume or pressure load and resistance and disrupts perfusion due to increased ventricular wall strain and myocardial oxygen requirement. Serum hscTnT levels are useful determinants for identifying PAH-related damage [38].

Despite advances in clinical and biological management of PAH, patient management and decision-making still continue to challenge us. As described in the above-mentioned studies, PAH biomarkers play a critical role in diagnostic, prognostic and therapeutic point of view. Routine clinical, functional and hemodynamic evaluations in PAH patients are important. With the addition of biomarkers, the clinical evaluation will be completed and a predictive and prognostic evaluation will be provided. Further studies are required to support these hypotheses.

\section{Evaluation of Hs-cTnT Levels in Chronic Kidney Disease}

Increased cardiac troponin levels in more than $99 \%$ of patients with the cerebrovascular disease can be frequently detected $[12,39]$ and cardiac insufficiency even in the absence of acute ischemia and in patients with early chronic kidney insufficiency (CKI) without symptomatic heart disease [40]. Observational studies reported that constantly elevated hs-c TnT predicts cardiovascular disease and mortality in asymptomatic CKI and dialysis-dependent patients [41, 42]. A large-scale observational study in the general population showed that non-atherosclerotic factors could be the primary cause of chronically detectable hs-c TnT concentrations [12].

In asymptomatic, geriatric patients with renal insufficiency minimally elevated hs-cTnT levels are associated with all-cause mortality [20]. Hickson et al. [43] showed that hs-c $\operatorname{Tn} \mathrm{T}$ provides prognostic information independently from conventional risk factors related to mortality and last stage renal insufficiency and basic kidney functions in all HT patients and potentially at high-risk. Increased hs-cTnT is an indicator of myocardial ischemia in addition to much cardiac pathology that is frequently present in patients with chronic kidney insufficiency. Moreover, hs-c TnT is an excellent indicator of survival in CKI patients [44]. Hs-cTnT level at the pre-transplantation stage is an important determinant of the post-renal transplantation survey [45]. 
A common misconception is that reduced clearance of hs-c $\operatorname{TnT}$ contributes to high levels in patients with CKD. However, the hypothesis that hs-c TnT is a large molecule and cannot be cleared by the kidneys is incorrect. Hs-cTnT has a molecular weight of $37 \mathrm{kDa}$. Troponin is released as free troponin or as a complex of troponin $\mathrm{T}$, troponin $\mathrm{C}$ and troponin I. Recent studies have shown that hs-cTnT is released into small molecules that can be broken down into fragments of myocardial cells and then detected by laboratory measurements. These fragments are small enough to be cleared by the kidneys and therefore, may be elevated in patients with renal failure due to delayed clearance. Immunoassays can detect not only proteolytic degradation products of troponins but also covalently bound troponin complexes [46].

The presence of elevated hs-c TnT levels in any patient with CKI may be due to underlying structural or symptomatic heart disease. It is difficult to distinguish whether high hs-cTnT levels are due to CKD or symptomatic heart disease. More studies are needed to describe the role of hs-c TnT in the clinical management of asymptomatic CKD patients and the mechanisms by which asymptomatic elevation of the hsc'TnT may occur.

\section{Evaluation of Hs-cTnT Levels in Cerebral Diseases}

Von Rennenberg et al. [47] investigated if there was a relation between subclinical cardiac disease and subclinical brain disease in patients with acute stroke. High levels of hs-cinT are associated with the extent of white matter lesions in acute stroke patients. The findings of this study are in parallel with the results of other studies showing an association between hs-c $\mathrm{Tn} \mathrm{T}$ and different biomarkers of cerebral small vessel disease in different populations. Hilal et al. [48] found a significant relation between hs-cTnT and cortical cerebral microinfarcts in memory clinic patients. Hs-cTnT levels are associated with poor outcomes in intubated patients with traumatic brain damage. In this patient group, serum hs-c $\operatorname{TnT}$ measurement at the time of admission to the intensive care unit is a useful tool for early risk classification and accelerated care [49].

Hs-c $\operatorname{Tn} \mathrm{T}$ can be an independent determinant for the formation of cerebral microbleeding, particularly for deep or infratentorial cerebral microbleeding. This finding justifies the studies on how hs-cTnT levels can contribute to cerebral microbleeding and potentially subclinical small vessel diseases [50].
Perhaps the usage of cardiovascular biomarkers, such as hs-cTnT with imaging methods, may help in the early prevention of cognitive function loss in cerebrovascular events.

\section{Conclusion}

In recent years, hs-c $\operatorname{Tn} T$ has become prominent as a noninvasive biomarker for the detection of myocardial damage. Ischemia associated with clinical findings confirms the diagnosis of myocardial infarction with increased blood cTnT levels. However, hs-c'TnT is not specifically released as a result of ischemic myocardial cell necrosis but is also released by many non-ischemic acute and chronic heart diseases, such as myopericarditis, toxic injury or severe cardiac overload. With high-precision assays, the causes of hs-c TnT elevation not only associated with the acute coronary syndrome (ACS) have become common in acute or chronic systemic disorder. High levels of hs-c $\operatorname{Tn} \mathrm{T}$ in the blood are associated with increased cardiac events and mortality rates independent of the underlying disease. However, the clinical conditions causing hs-cTnT secretion in patients without ACS and the appropriate diagnosis and treatment strategies for these individuals are largely unknown. In this review, we aimed to provide an overview of many causes and prognostic significance of non-ACS-related hs-cTnT release. We also tried to raise awareness that hs-c TnT elevation not only focused on cardiac events but also high hs-c TnT levels were observed in other acute events. Perhaps the use of cardiovascular biomarkers such as $\mathrm{Hs}-\mathrm{c} \operatorname{Tn} \mathrm{T}$ may help in the early prevention of non-cardiac diseases. Further studies are required to support these hypotheses.

Conflict of Interest: No conflict of interest was declared by the authors.

Financial Disclosure: The authors declared that this study has received no financial support.

Authorship Contributions: Concept - LA, OT, ST; Design - LA, OT, ST; Supervision - LA, OT, ST; Data collection and/or processing - LA, OT, ST; Analysis and/or interpretation - LA, OT, ST; Literature review - LA, OT, ST; Writing - LA, ST; Critical review - LA, ST.

\section{REFERENCES}

1. Dubin RF, Li Y, He J, Jaar BG, Kallem R, Lash JP, et al; CRIC Study Investigators. Predictors of high sensitivity cardiac troponin $\mathrm{T}$ in chronic kidney disease patients: a cross-sectional study in the chronic renal insufficiency cohort (CRIC). BMC Nephrol 2013;14:229. [CrossRef]

2. Wu W, Li DX, Wang Q, Xu Y, Cui YJ. Relationship between high-sensitivity cardiac troponin $\mathrm{T}$ and the prognosis of elderly inpatients with 
non-acute coronary syndromes. Clin Interv Aging 2018;13:1091-8.

3. Thygesen K, Mair J, Mueller C, Huber K, Weber M, Plebani M, et al; Study Group on Biomarkers in Cardiology of the ESC Working Group on Acute Cardiac Care. Recommendations for the use of natriuretic peptides in acute cardiac care: a position statement from the Study Group on Biomarkers in Cardiology of the ESC Working Group on Acute Cardiac Care. Eur Heart J 2012;33:2001-6. [CrossRef]

4. Vasile VC, Saenger AK, Kroning JM, Jaffe AS. Biological and analytical variability of a novel high-sensitivity cardiac troponin T assay. Clin Chem 2010;56:1086-90. [CrossRef]

5. Cardinaels EP, Daamen MA, Bekers O, ten Kate J, Niens M, van Suijlen JD, et al. Clinical Interpretation of Elevated Concentrations of Cardiac Troponin T, but Not Troponin I, in Nursing Home Residents. J Am Med Dir Assoc 2015;16:884-91. [CrossRef]

6. de Lemos JA, Drazner MH, Omland T, Ayers CR, Khera A, Rohatgi A, et al. Association of troponin T detected with a highly sensitive assay and cardiac structure and mortality risk in the general population. JAMA 2010;304:2503-12. [CrossRef]

7. Macedo ME, Lima MJ, Silva AO, Alcantara P, Ramalhinho V, Carmona J. Prevalence, awareness, treatment and control of hypertension in Portugal: the PAP study. J Hypertens 2005;23:1661-6. [CrossRef]

8. Melander O, Newton-Cheh C, Almgren P, Hedblad B, Berglund G, Engström G, et al. Novel and conventional biomarkers for prediction of incident cardiovascular events in the community. JAMA 2009;302:4957. [CrossRef]

9. Selvin E, Lazo M, Chen Y, Shen L, Rubin J, McEvoy JW, et al. Diabetes mellitus, prediabetes, and incidence of subclinical myocardial damage. Circulation 2014;130:1374-82. [CrossRef]

10. Çaylı M, Gür M, Elbasan Z, Şeker T, Türkoğlu C, Kaypaklı O, et al. High-sensitivity cardiac troponin $\mathrm{T}$ predicts nondipper hypertension in newly diagnosed hypertensive patients. J Clin Hypertens (Greenwich) 2013;15:731-6. [CrossRef]

11. Sato Y, Yamamoto E, Sawa T, Toda K, Hara T, Iwasaki T, et al. Highsensitivity cardiac troponin $\mathrm{T}$ in essential hypertension. J Cardiol 2011;58:226-31. [CrossRef]

12. Saunders JT, Nambi V, de Lemos JA, Chambless LE, Virani SS, Boerwinkle E, et al. Cardiac troponin $\mathrm{T}$ measured by a highly sensitive assay predicts coronary heart disease, heart failure, and mortality in the Atherosclerosis Risk in Communities Study. Circulation 2011;123:1367-76. [CrossRef]

13. Høiseth AD, Omland T, Hagve TA, Brekke PH, Søyseth V. Determinants of high-sensitivity cardiac troponin $\mathrm{T}$ during acute exacerbation of chronic obstructive pulmonary disease: a prospective cohort study. BMC Pulm Med 2012;12:22. [CrossRef]

14. Erdogan D, Gullu H, Caliskan M, Yildirim I, Baycan S, Ciftci O, et al. The influence of circadian blood pressure changes on aortic distensibility and left ventricular diastolic function in hypertensive individuals. Int J Cardiovasc Imaging 2006;22:157-65. [CrossRef]

15. McEvoy JW, Chen Y, Nambi V, Ballantyne CM, Sharrett AR, Appel LJ, et al. High-Sensitivity Cardiac Troponin T and Risk of Hypertension. Circulation 2015;132:825-33. [CrossRef]

16. Askin L, Yesiltepe Y. High-Sensitivity Cardiac Troponin T levels in prehypertensive patients. Clin Exp Hypertens 2018;40:332-6. [CrossRef]

17. Askin L, Tasolar H, Aksu U, Cetin M, Uslu A, Tanboga HI, et al. Discerning the relationship between left ventricular geometry, high-sensitivity troponin T, and nondipper hypertension. Blood Press Monit 2018;23:12-8. [CrossRef]

18. Camici PG, Crea F. Coronary microvascular dysfunction. N Engl J Med 2007;356:830-40. [CrossRef]
19. Setsuta K, Kitahara Y, Arae M, Ohbayashi T, Seino Y, Mizuno K. Elevated cardiac troponin $\mathrm{T}$ predicts adverse outcomes in hypertensive patients. Int Heart J 2011;52:164-9. [CrossRef]

20. Mishra RK, Li Y, DeFilippi C, Fischer MJ, Yang W, Keane M, et al; CRIC Study Investigators. Association of cardiac troponin $\mathrm{T}$ with left ventricular structure and function in CKD. Am J Kidney Dis 2013;61:701-9. [CrossRef]

21. Hickman PE, Koerbin G, Badrick T, Oakman C, Potter JM. The importance of low level QC for high sensitivity troponin assays. Clin Biochem 2018;58:60-3. [CrossRef]

22. Apple FS, Ler R, Murakami MM. Determination of 19 cardiac troponin I and $\mathrm{T}$ assay $99^{\text {th }}$ percentile values from a common presumably healthy population. Clin Chem 2012;58:1574-81. [CrossRef]

23. Bai Y, Ye P, Luo L, Xiao W, Xu R, Wu H, et al. Arterial stiffness is associated with minimally elevated high-sensitivity cardiac, troponin $\mathrm{T}$ levels in a community-dwelling population. Atherosclerosis 2011;218:493-8.

24. Pons-Lladó G, Ballester M, Borrás X, Carreras F, Carrió I, López-Contreras J, et al. Myocardial cell damage in human hypertension. J Am Coll Cardiol 2000;36:2198-203. [CrossRef]

25. Tamura T, Said S, Lu W, Harris J, Neufeld D, Burbach JA, et al. Is apoptosis present in progression to chronic hypertensive heart failure? J Card Fail 2000;6:37-42. [CrossRef]

26. Uçar H, Gür M, Kivrak A, Koyunsever NY, Seker T, Akilli RE, et al. High-sensitivity cardiac troponin T levels in newly diagnosed hypertensive patients with different left ventricle geometry. Blood Press 2014;23:240-7. [CrossRef]

27. Hellemons ME, Lambers Heerspink HJ, Gansevoort RT, de Zeeuw D, Bakker SJ. High-sensitivity troponin T predicts worsening of albuminuria in hypertension; results of a nested case-control study with confirmation in diabetes. J Hypertens 2013;31:805-12. [CrossRef]

28. Kaypakli O, Gür M, Gözükara MY, Uçar H, Kivrak A, Şeker T, et al. Association between high-sensitivity troponin T, left ventricular hypertrophy, and myocardial performance index. Herz 2015;40:1004-10.

29. Filusch A, Giannitsis E, Katus HA, Meyer FJ. High-sensitive troponin $\mathrm{T}$ : a novel biomarker for prognosis and disease severity in patients with pulmonary arterial hypertension. Clin Sci (Lond) 2010;119:207-13. [CrossRef]

30. Giannitsis E, Müller-Bardorff M, Kurowski V, Weidtmann B, Wiegand $\mathrm{U}$, Kampmann $\mathrm{M}$, et al. Independent prognostic value of cardiac troponin $\mathrm{T}$ in patients with confirmed pulmonary embolism. Circulation 2000;102:211-7. [CrossRef]

31. Konstantinides S, Geibel A, Olschewski M, Kasper W, Hruska N, Jäckle $S$, et al. Importance of cardiac troponins $I$ and $T$ in risk stratification of patients with acute pulmonary embolism. Circulation 2002;106:1263-8. [CrossRef]

32. Torbicki A, Kurzyna M, Kuca P, Fijałkowska A, Sikora J, Florczyk M, et al. Detectable serum cardiac troponin $\mathrm{T}$ as a marker of poor prognosis among patients with chronic precapillary pulmonary hypertension. Circulation 2003;108:844-8. [CrossRef]

33. Clerico A, Giannoni A, Prontera C, Giovannini S. High-sensitivity troponin: a new tool for pathophysiological investigation and clinical practice. Adv Clin Chem 2009;49:1-30. [CrossRef]

34. Borges AC, Knebel F, Eddicks S, Panda A, Schattke S, Witt C, et al. Right ventricular function assessed by two-dimensional strain and tissue Doppler echocardiography in patients with pulmonary arterial hypertension and effect of vasodilator therapy. Am J Cardiol 2006;98:530-4. [CrossRef]

35. Rajagopalan N, Simon MA, Shah H, Mathier MA, López-Candales A. Utility of right ventricular tissue Doppler imaging: correlation with 
right heart catheterization. Echocardiography 2008;25:706-11.

36. Kriechbaum SD, Wiedenroth CB, Keller T, Wolter JS, Ajnwojner R, Peters $\mathrm{K}$, et al. Dynamics of high-sensitivity cardiac troponin $\mathrm{T}$ during therapy with balloon pulmonary angioplasty for chronic thromboembolic pulmonary hypertension. PLoS One 2018;13:e0204683. [CrossRef]

37. Mair J. High-sensitivity cardiac troponins in everyday clinical practice. World J Cardiol 2014;6:175-82. [CrossRef]

38. Kayali S, Ertugrul I, Yoldas T, Kaya O, Ozgür S, Orün UA, et al. Sensitive Cardiac Troponins: Could They Be New Biomarkers in Pediatric Pulmonary Hypertension Due to Congenital Heart Disease? Pediatr Cardiol 2018;39:718-25. [CrossRef]

39. Wallace TW, Abdullah SM, Drazner MH, Das SR, Khera A, McGuire DK, et al. Prevalence and determinants of troponin $T$ elevation in the general population. Circulation 2006;113:1958-65. [CrossRef]

40. Ford ML, Smith ER, Tomlinson LA, Chatterjee PK, Rajkumar C, Holt SG. FGF-23 and osteoprotegerin are independently associated with myocardial damage in chronic kidney disease stages 3 and 4 . Another link between chronic kidney disease-mineral bone disorder and the heart. Nephrol Dial Transplant 2012;27:727-33. [CrossRef]

41. Wang AY, Lam CW, Wang M, Chan IH, Goggins WB, Yu CM, et al. Prognostic value of cardiac troponin $\mathrm{T}$ is independent of inflammation, residual renal function, and cardiac hypertrophy and dysfunction in peritoneal dialysis patients. Clin Chem 2007;53:882-9. [CrossRef]

42. Abbas NA, John RI, Webb MC, Kempson ME, Potter AN, Price CP, et al. Cardiac troponins and renal function in nondialysis patients with chronic kidney disease. Clin Chem 2005;51:2059-66. [CrossRef]

43. Hickson LJ, Rule AD, Butler KR Jr, Schwartz GL, Jaffe AS, Bartley
AC, et al. Troponin T as a Predictor of End-Stage Renal Disease and All-Cause Death in African Americans and Whites From Hypertensive Families. Mayo Clin Proc 2015;90:1482-91. [CrossRef]

44. Apple FS, Murakami MM, Pearce LA, Herzog CA. Predictive value of cardiac troponin I and $\mathrm{T}$ for subsequent death in end-stage renal disease. Circulation 2002;106:2941-5. [CrossRef]

45. Keddis MT, El-Zoghby ZM, El Ters M, Rodrigo E, Pellikka PA, Jaffe AS, et al. Cardiac troponin $T$ before and after kidney transplantation: determinants and implications for posttransplant survival. Am J Transplant 2013;13:406-14. [CrossRef]

46. Diris JH, Hackeng CM, Kooman JP, Pinto YM, Hermens WT, van Dieijen-Visser MP. Impaired renal clearance explains elevated troponin $T$ fragments in hemodialysis patients. Circulation 2004;109:23-5.

47. von Rennenberg R, Siegerink B, Ganeshan R, et al. High-sensitivity cardiac troponin $\mathrm{T}$ and severity of cerebral white matter lesions in patients with acute ischemic stroke. J Neurol 2019;266:37-45. [CrossRef]

48. Hilal S, Chai YL, van Veluw S, Shaik MA, Ikram MK, Venketasubramanian N, et al. Association Between Subclinical Cardiac Biomarkers and Clinically Manifest Cardiac Diseases With Cortical Cerebral Microinfarcts. JAMA Neurol 2017;74:403-10. [CrossRef]

49. El-Menyar A, Asim M, Latifi R, Bangdiwala SI, Al-Thani H. Predictive value of positive high-sensitivity troponin $\mathrm{T}$ in intubated traumatic brain injury patients. J Neurosurg 2018;129:1541-9. [CrossRef]

50. Liu J, Wang D, Xiong Y, Liu B, Wei C, Ma Z, et al. High-sensitivity cardiac troponin $T$ levels and risk of cerebral microbleeds in acute ischemic stroke patients with atrial fibrillation and/or rheumatic heart disease. J Neurol Sci 2016;369:15-8. [CrossRef] 